\title{
The Multidimensional Structure of Subjective Well-Being In Later Life
}

\author{
Bram Vanhoutte
}

Received: 3 May 2013 / Accepted: 9 January 2014 /Published online: 29 January 2014

(C) Springer Science+Business Media Dordrecht 2014

\begin{abstract}
Subjective well-being can be measured in different ways, depending on the conceptual perspective one adopts. Hedonic well-being, emphasising emotions and evaluation, is often contrasted with eudemonic well-being, stressing self-actualisation and autonomy. In this paper we investigate the background, structure and compatibility of empirical measures of hedonic and eudemonic well-being in the English Longitudinal Study of Ageing (ELSA). We use a confirmatory factor approach to investigate the internal of structure of the General Health Questionnaire (GHQ), Centre for Epidemiological Studies Depression scale (CES-D), Satisfaction with Life scale (SWLS) and CASP, a measure of quality of life in old age. In a second step, we examine the higher order structure of well-being using these measures. Next to highlighting specific issues about the structure of these measures in connection to older populations, we illustrate that a threefold structure, distinguishing affective, cognitive and eudemonic aspects of well-being, is more informative than the two dimensional hedonic and eudemonic well-being that is often propagated.
\end{abstract}

Keywords Subjective well-being · Confirmatory factor analysis · Measurement

\section{Introduction}

Health, as defined by the World Health Organisation (WHO), goes beyond the mere absence of disease, but includes physical, mental and social well-being. The framework of healthy and successful ageing (Rowe and Kahn 1997), therefore encompasses multiple dimensions, spanning both biological and social sciences. A biomedical model of successful ageing strives for an old age free from disability and disease, with high levels of cognitive and physical function. The psycho-social approach emphasizes subjective well-being and psychological resources as the key to a good old age, which is more in line with lay conceptions (Bowling and Dieppe 2005; Strawbridge et al.

B. Vanhoutte $(\bowtie)$

Cathie Marsh Institute for Social Research, School of Social Sciences, University of Manchester,

Manchester, UK

e-mail: Bram.vanhoutte@manchester.ac.uk 
2002). The diagnosis of disease and measurement of physical and cognitive function is relatively standardized, objective and structured as it is mainly assessed by health professionals. Measurement of subjective well-being is less straightforward, and forms the base of a quite complex and substantial debate on what exactly the good life entails: the pursuit of happiness and adaptation to the ever changing circumstances of life, or the fulfilment of human potential (Deci and Ryan 2006).

This paper aims to support research on the psycho-social dimension of successful ageing, and serves a dual purpose. Firstly, it provides a critical overview of the theoretical and technical adequacy of existing survey measures of subjective wellbeing for the elderly. Established measures of depressive symptoms, mental health, satisfaction with life and quality of life are investigated in the framework of subjective well-being in later life. Secondly, it explores to what extent these specific measures can be combined, so a grounded evaluation of the similarity or dissimilarity of these particular aspects of subjective well-being in later life can be made. This analysis will make use of wave three of the English Longitudinal Study of Ageing (ELSA) in a confirmatory factor analysis (CFA) framework. In the first step of our analysis, each measure is examined separately and in detail, whereas in the second step all measures are examined together in a second order framework. In the conclusions, the relevance of a multidimensional approach to well-being for older adults is evaluated in the light of competing claims on the nature of well-being.

\section{Two Approaches to Subjective Well-Being}

In this first part, the survey measures that form the heart of this paper are introduced by highlighting conceptual origins, measurement aspects and issues relating to later life. All measures are situated in relation to the two dominant research traditions in subjective well-being: hedonic and eudemonic well-being (Deci and Ryan 2006; Delle Fave et al. 2010; Waterman 2007).

The foundation of the enduring philosophical argument between these different conceptualisations of the good life is often attributed to classical Greek philosophy, but remains salient in our times (Henderson and Knight 2012; Kashdan et al. 2008; Waterman 2008). Hedonic well-being has less to do with the pure pleasure seeking associated with the Cyrenaic school, but more with finding a positive balance by seeking modest pleasure while avoiding pain, as Epicurus preached (Waterman 1993). The idea of balancing out pleasure and pain, to have a measurable quantity of well-being that could help us decide if an action is good or not, lies at the heart of Bentham's idea of the hedonistic calculus of utility, the foundational concept of economics. Currently, the hedonic conception of well-being is embraced by economists who investigate the effect of economic growth (Easterlin 1974), and psychologists who highlight the role of expectations in satisfaction (Kahneman et al. 2006), and as such has been picked up by policy makers on different levels (Beaumont 2011; OECD 2011; Stiglitz et al. 2009). Hedonic well-being is sometimes equated with subjective wellbeing altogether, thanks to the clear structuring of the theoretical framework by psychologist Ed Diener (Diener et al. 1999; Diener 1984). Eudemonia, best translated as human flourishing, is often traced back to Aristotle's Nichomachean Ethics, where it is positioned against mere physical, animal-like enjoyment as the base for a good, 
virtuous life (Deci and Ryan 2006; Ryff et al. 2004; Ryff 1989). The idea that fulfilment of one's potential in the form of self-actualisation is the summit of personal development is reflected in the fact that it is the highest need in Maslow's need hierarchy (Maslow 1968). More recently, the positive psychology movement (Seligman and Csikszentmihalyi 2000) take this striving for human flourishing as its point for departure. Eudemonic well-being is sometimes labelled psychological well-being, to clearly distinguish it from Diener's subjective well-being (Ryff and Keyes 1995; Ryff and Singer 1998).

\section{Hedonic Well-Being}

The hedonic view on well-being assumes that through maximizing pleasurable experiences, and minimizing suffering, the highest levels of well-being can be achieved. This emphasis on pleasure and stimulation entails not only bodily or physical pleasures, but allows any pursuit of goals or valued outcomes to lead to happiness. Both cognitive and affective aspects of well-being can be identified within this approach (Diener 1984) (Fig. 1). A high level of well-being in the hedonic approach consists of a high life satisfaction, the presence of positive affect and the absence of negative affect (Diener 1984). Well-being resides within the individual (Campbell et al. 1976), and therefore does not include reference to objective realities of life, such as health, income, social relations or functioning.

The affective aspect of hedonic well-being consists of moods and emotions, both positive and negative. Positive and negative affect each form a separate domain, and are not just opposites (Watson et al. 1988). Positive affect (PA) is a state wherein an individual feels enthusiastic, active and alert. High PA means high energy, full concentration and pleasurable engagement, while low PA encompasses sadness and lethargy. Negative affect (NA) generally captures subjective distress and unpleasant mood states, such as anger, disgust, guilt, fear and nervousness. Low (NA) on the other hand encompasses calmness and serenity. Both positive and negative affect are usually measured by letting the respondent assess the prevalence of a number of emotional states in the last month (Watson et al. 1988). The affective approach to well-being urges us to see mental health not only in connection to disorders but equally as a path to flourishing (Bradburn 1969). This brings its measurement very close to assessing mental health. Therefore it is not surprising that depressive symptoms are sometimes

Fig. 1 Schematic representation of measures of hedonic well-being

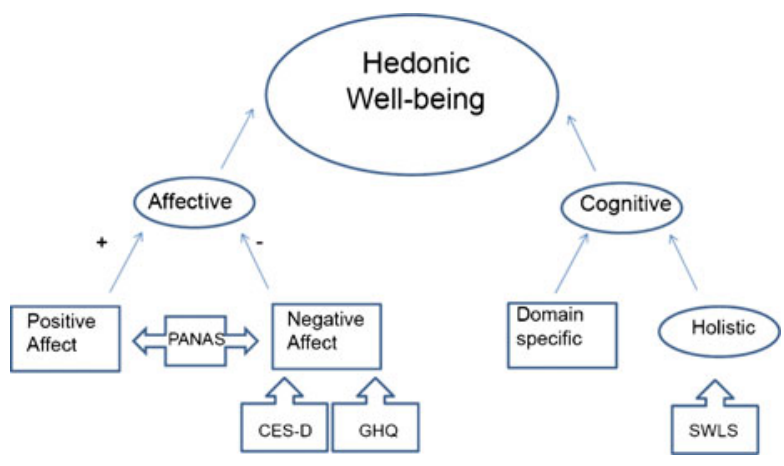


used as a measure of NA (Demakakos et al. 2010). Although a depressive episode is not characterised by depressive mood alone, an enduring low mood is its key feature. NA encompasses many more emotions than only depressed mood, but in connection to subjective well-being depressed mood is the most pertinent negative affective state. The prevalence of depressive symptoms is commonly assessed by the Centre for Epidemiological Studies Depression (CES-D) scale (Radloff 1977). A second measure for mental health, the 12 item version of the General Health Questionnaire (GHQ) (Goldberg 1988) can be seen in the light of affective measures as well. The main difference between both measures is that GHQ is explicitly meant to capture minor depressive episodes, while CES-D is aimed at detecting major depressive episodes.

Some attention is needed when using these measures of emotional health in older populations, for two reasons. Firstly, some studies report more somatic symptoms than emotional moods of depression by older adults (King and Markus 2000). As depression is not a monolithic disease, but an emotional disorder accompanied by physiological symptoms, it can be difficult to distinguish it from conditions in later life that trigger similar symptoms, such as chronic illness or cognitive impairment (Lebowitz et al. 1997). Secondly, major depression is less prevalent among the elderly (2\%), while minor depression ( $15 \%$ ) is relatively common, and closely interrelated with stressful life events in later life and vascular risk factors (Beekman and Deeg 1995; Van den Berg et al. 2001). Together, these findings have led to the challenged idea that depression manifests itself in a different way among older adults, as a phenomenon called later life depression (Alexopoulos 2005; Lebowitz et al. 1997). In addressing these issues, it is helpful to make a distinction between somatic and mood aspects of depression on one hand, and to look at depression as a continuum rather than using a threshold of a number of symptoms to determine who is depressed and who isn't.

The cognitive component of hedonic well-being, often referred to as life satisfaction, is a judgemental process in which individuals asses the quality of their life based on their own set of criteria (Pavot and Diener 1993). In contrast to domain specific evaluations of satisfaction (Campbell et al. 1976) an idiosyncratic set of standards and weights is taken into account. This allows comparing satisfaction with life over groups of people with different aspirations in life. The Satisfaction With Life Scale (SWLS) (Diener et al. 1985; Pavot and Diener 1993) consists of 5 items to be rated on a response scale ranging from 1 (strongly disagree) to 7 (strongly agree), inviting respondents to make a global evaluation of their life. From a methodological perspective, it is surprising that all the items are worded in a positive way, because this way the scale could suffer from extreme responses and acquiescence bias. Often, at least one item is worded in a negative sense, to avoid respondents answering without really thinking about the question asked.

Perceptions about the self and one's own life tend to be too positive and optimistic (Kahneman and Thaler 2006; Taylor and Brown 1988), so that hedonic well-being ultimately depends on how high or low one sets his goals. This judgemental relativity can be seen as a major problem in relation to ageing, as changes in life satisfaction could well reflect hidden changes in the goals one sets, or one's reference group. Similarly, adaptation plays a main role in the cognitive process of accepting the circumstances as they are and moving to a normal level of well-being. A second severe criticism on well-being as maximizing pleasure, is that negative events, such as losing a spouse, or diminishing physical health have an important role in providing insight about one-self, or growing as a person (Ryff and Singer 1998). 


\section{Eudemonic Well-Being}

A second approach starts from a different concept of well-being. The good life is not just about pleasure and happiness, but involves developing one-self and realizing one's potential (Ryff and Keyes 1995). Eudemonic well-being reflects positive functioning and personal expressiveness, aspects of life that have been gaining in importance in late modernity (Giddens 1991; Inglehart 1997). As the concept of positive functioning is less strictly defined than the evaluational, balancing hedonic approach, several different measurement instruments were developed alongside each other. Ryan and Deci (2000) conceptualize it in their self-determination theory (SDT) and see autonomy, competence and relatedness as three basic necessities for personal growth, integrity and wellbeing. By looking at six distinct aspects of actualisation (autonomy, personal growth, self-acceptance, life purpose, mastery and positive relatedness), Ryff and Keyes (1995) measure psychological well-being (PWB), which they see separate from subjective well-being. In the framework of studies on later life, a measure specifically targeted to measure quality of life for older populations has been developed (Hyde et al. 2003). Four constructs, namely Control, Autonomy, Self-realization and Pleasure (CASP) together can be seen as an accurate measure of positive functioning, and subjective quality of life in later life. An explicit aim of this measure was to distinguish quality of life from its drivers such as health (Hyde et al. 2003). Therefore it is quite surprising to see explicit references to the respondents' age and health, in some items from the scale.

Comparing the dimensionality of different conceptualisations of eudemonic wellbeing, it becomes clear that in large lines they rely on very similar concepts (see Table 1). All three approaches depart from the idea that human flourishing depends on the satisfaction of certain psychological needs. Autonomy is a need that is present explicitly in PWB, SDT and CASP. Both control in CASP, and environmental mastery in PWB can be seen as closely related concepts, relating to autonomy. The second key aspect of eudemonic well-being is developing one-self, and is captured as personal growth in PWB, as competence in SDT and self-realisation in CASP. The largest difference between the three approaches is that both PWB and SDT do not see pleasure, or any other aspect of Diener's hedonic concepts as an explicit psychological need (Diener et al. 1998; Ryff and Singer 1998), while CASP does. While Ryff and Singer (1998) downplay the importance of hedonic well-being altogether, Ryan and Deci (2001) see it as a consequence of the fulfilment of needs that goes hand in hand with eudemonic well-being. Secondly, relatedness, or having warm and positive social

Table 1 Overview of dimensions of eudemonic well-being

\begin{tabular}{lll}
\hline $\begin{array}{l}\text { PWB (Ryff and } \\
\text { Keyes 1995) }\end{array}$ & $\begin{array}{l}\text { SDT (Ryan and } \\
\text { Deci 2000) }\end{array}$ & $\begin{array}{l}\text { CASP 19 } \\
\text { (Hyde et al. 2003) }\end{array}$ \\
\hline $\begin{array}{l}\text { Autonomy } \\
\text { Personal growth }\end{array}$ & $\begin{array}{l}\text { Autonomy } \\
\text { Competence }\end{array}$ & $\begin{array}{l}\text { Autonomy } \\
\text { Self-realisation }\end{array}$ \\
$\begin{array}{l}\text { Life purpose } \\
\text { Environmental mastery }\end{array}$ & & \\
Positive relatedness & Relatedness & Control \\
& & Pleasure
\end{tabular}


relations, is seen as an essential need for psychological well-being, while it is not explicitly defined in the CASP scale.

\section{Data and Methods}

We will make use of the information contained in wave three (2006) of ELSA ${ }^{1}$. While ELSA is set up as a longitudinal study, specific efforts are taken to ensure that each wave is representative of community residing inhabitants of England aged 50 or more (Marmot et al. 2011; Scholes et al. 2009). Most well-being measures are included in the drop-off questionnaire, to increase reliability of these sensitive personal questions, and reduce social desirability in answering. Therefore the analysis is limited to respondents who answered the self-completion questionnaire, in total 8244 respondents (or $84.4 \%$ of the total sample). Wave three is used because all measures were present in that wave simultaneously. Exact item wording, item response and answering categories of each measure can be found in the Appendix.

The structure of the scales is examined using factor analysis. Two main forms of factor analysis can be distinguished: exploratory factor analysis (EFA) and confirmatory factor analysis (CFA). EFA is more data-driven, and is often used in scale development, when there is little underlying theory on how items should load on a factor, or how many factors are present. CFA is used to test and confirm theoretical hypotheses on scale structure, as is the case in this paper. An ideal scale structure in the first place consists of high factor loadings across the items that define it. A second, connected issue is the number of factors, or sub dimensions that exist in a scale. In EFA, the data provides the number of dimensions asked and it's up to the researcher to determine the threshold. The extensive use of EFA has been criticized, as it assumes that variables are measured without any form of systemic measurement error (Brown 2006). A false number of factors can surface if these method effects are not taken into account (Brown 2003; Chen et al. 2010; DiStefano and Motl 2009; Hankins 2008; Van de Velde et al. 2010; Wood et al. 2010).

One important aspect to help us decide which model fits better is the test statistics and their thresholds. A number of different fit indexes situate the model on a continuum of good to bad model fit, but as opinions differ on their cut-off points, they should be seen in combination rather than isolated, and as guidelines more than absolutes (Ariely and Davidov 2011; Bollen 1989; Hu and Bentler 1999; Meredith 1993). Absolute fit indexes, such as the root means square error of approximation (RMSEA), assesses how good an a priori model reproduces the sample data by comparing it the an ideal best fitting model, while incremental fit indexes, such as the Tucker-Lewis Index (TLI) and Comparative Fit Index (CFI), compare the target model with a more restricted baseline model as well as an ideal best fitting model. Generally accepted cut-off points for RMSEA are 0.06 or lower for excellent fit, and 0.08 or lower for decent fit, and higher

\footnotetext{
${ }^{1}$ The data were made available through the UK Data Archive (UKDA). ELSA was developed by a team of researchers based at the National Centre for Social Research, University College London and the Institute for Fiscal Studies. The data were collected by the National Centre for Social Research. The funding is provided by the National Institute of Aging in the United States, and a consortium of UK government departments coordinated by the Office for National Statistics. The developers and funders of ELSA and the Archive do not bear any responsibility for the analyses or interpretations presented here.
} 
than 0.90 or higher than 0.95 for CFI and TLI (Hu and Bentler 1999). Modification indexes can help us detect which parts of the model are problematic in case fit models do not fit the data very well. All analysis is conducted in Mplus (Muthén and Muthén 2010), using WLSMV estimation as our items are categorical in nature.

\section{Analysis}

This paper analyses two aspects of the measurement of well-being. In a first step the structure for several aspects of subjective well-being, reflected in different scales is investigated. While some scales were specifically designed for an older population (CASP), other measures (SWLS, CES-D, GHQ) are designed for the general population. Therefore it is important to look at the structure of these scales specifically for an older population, and to investigate if they function in the same way as they do in the general population. In a second step, a second-order model of well-being is constructed, to see how the different sub-dimensions relate to each other. Can two main dimensions of subjective well-being, a eudemonic and a hedonic form of well-being be distinguished, or is a different conceptual framework more suited when investigating wellbeing in later life?

\section{Assessing Measurement}

Understanding the differences between the model specifications is key to grasping how confirmatory factor analysis is used to test theoretical models, therefore a schematic representation of different model specifications is shown below, using the example of the 19 item CASP scale (Figs. 2, 3, 4, 5, and 6). The baseline model (Fig. 2) assumes all

Fig. 21 factor model for CASP 19

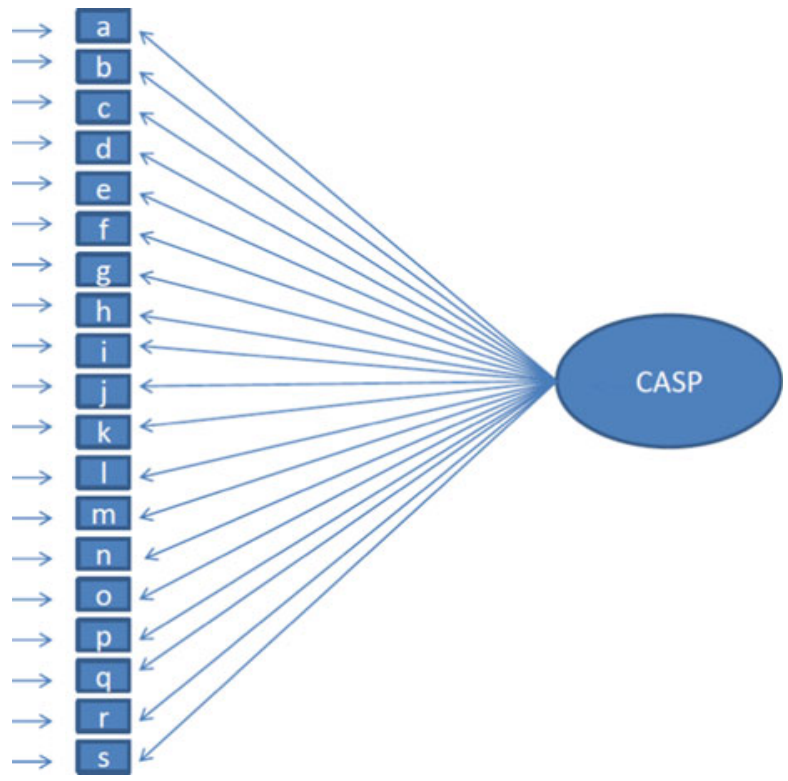


Fig. 31 factor model for CASP 19 with error correlations

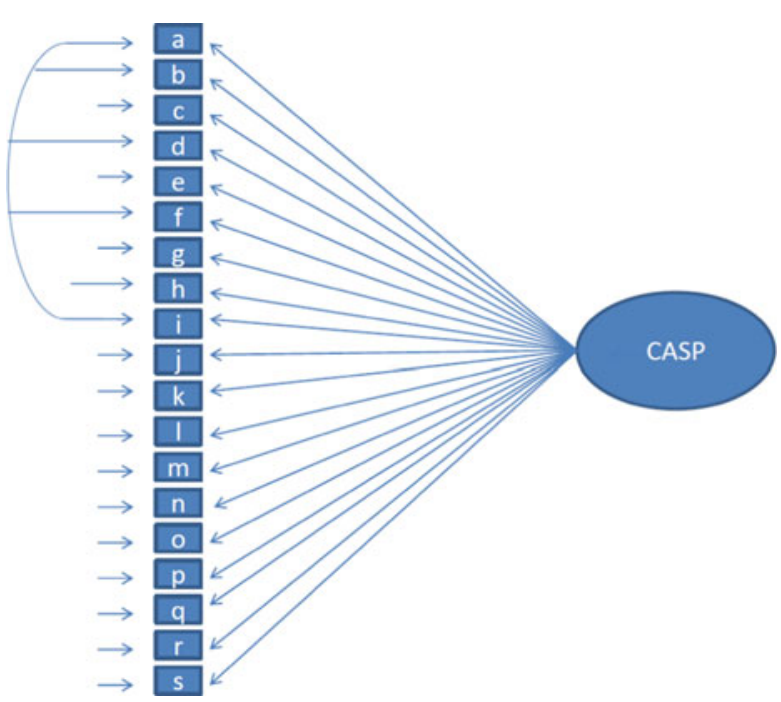

items load onto the same single factor. Each item is associated with an item-specific error term, which represents the variation that is not accounted for by the latent factor, in this case the CASP scale. Items posed in a negative manner can provoke different answers of a respondent, not due to the substantive matter but rather to the fact that the item is worded negatively (Marsh 1996). Asking someone 'how often are you unhappy' is not simply the inverse of 'how often are you happy'. To account for the possible measurement bias introduced by this inverse item wording, two possible specifications are used interchangeably in the literature. A first option is to allow correlations between

Fig. 41 factor model for CASP 19 with method factor for negatively worded items

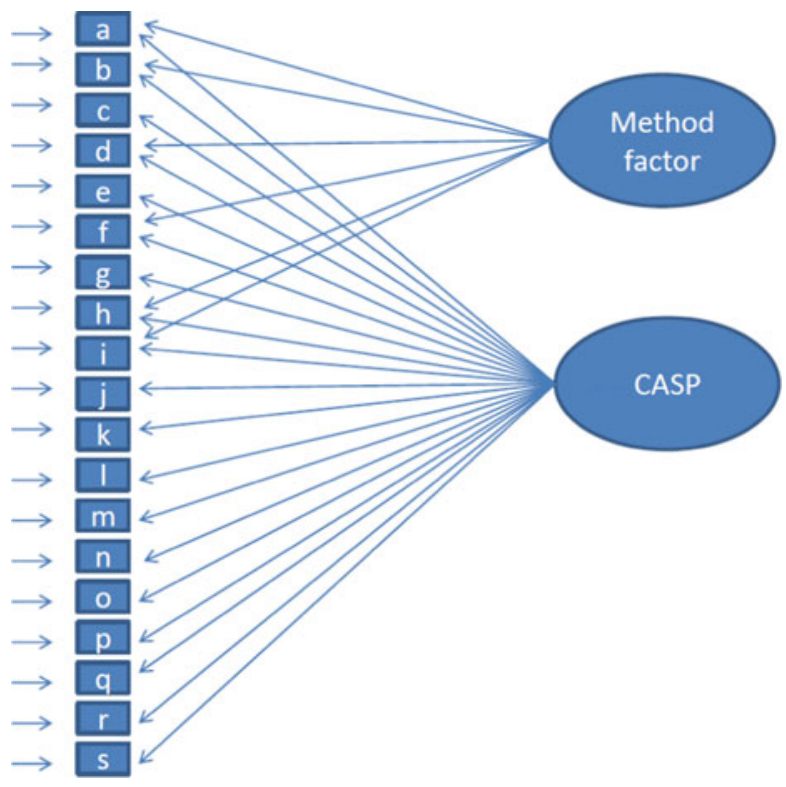


Fig. 52 factor model for CASP 19

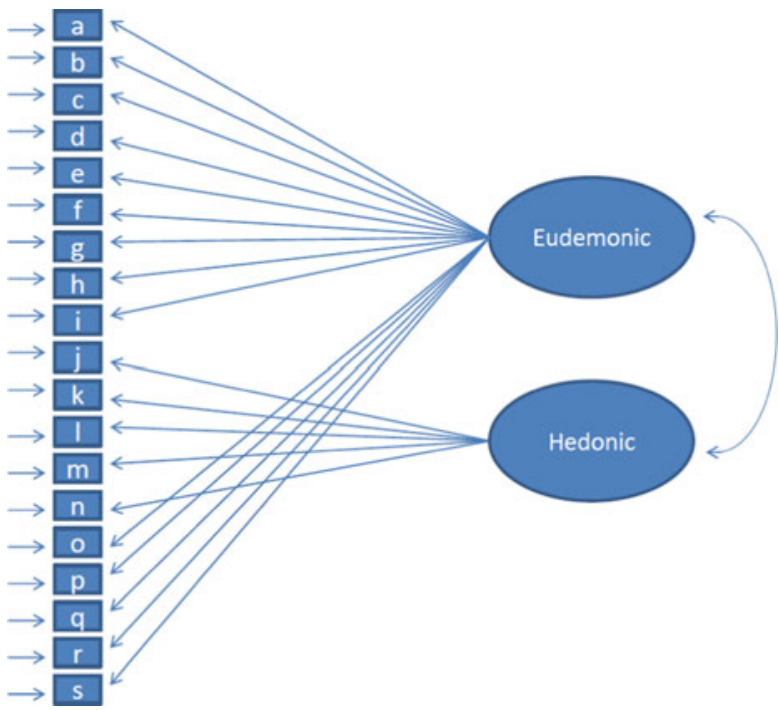

the error terms of the items that are phrased negatively (Fig. 3). A second, more restricting option, is to specify a latent 'method' factor onto which these items load, next to their loading onto the substantive factor (Fig. 4). If less than three items are phrased negatively, only error correlations are possible since a factor needs at least three items to be identified. As the dimensionality of CASP is also a point of interest, different specifications are tested. A division between eudemonic and hedonic aspects of well-being can be expected following the literature, so a two factor solution, isolating pleasure from control, autonomy, and self-actualisation, should also be tested (Fig. 5). The best fitting model for CASP in other studies (Vanhoutte 2012; Wiggins et al. 2008), distinguishing three dimensions, is also specified (Fig. 6). Multidimensional models can equally be specified with a method factor or error correlations.

Fig. 63 factor model for CASP 19

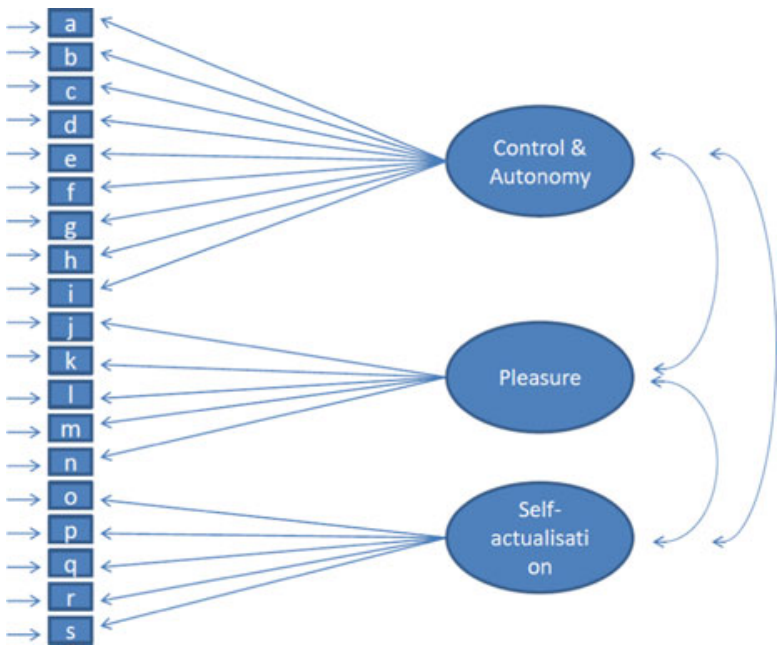


CASP

The CASP scale, in its original form is composed of 19 items, but revised forms of 12 items (Wiggins et al. 2008) and 15 items (Vanhoutte 2012) have been proposed for use. CASP is present in the self-completion questionnaire in its 19 item form. As often individual items are not mentioned when using a scale, it is relevant to investigate the structure of the latent concept in all versions of the scale. In the original study that tested the qualities of the CASP scale, a four dimensional structure was proposed for the 19 item scale, and both a two dimensional (Sexton et al. 2013) and three dimensional structure have been proposed for both the 12 and 15 item version (Vanhoutte 2012; Wiggins et al. 2008). Table 2 illustrates the results for these different configurations of the 15 item version of the CASP scale.

In the best fitting solution, with three factors, each dimension is measured by 5 items, and error correlations are allowed between negatively phrased items. It is also clear that the negative item wording has an effect on the model, and as such should be taken into account.

\section{$C E S-D$}

The original CES-D scale (Radloff 1977) comprises 20 items, but shorter versions are frequently used and have shown to be equivalent (Kohout et al. 1993). In ELSA an 8 item version is used. When looking at the CES-D scale in its extended form with EFA, four sub-dimensions surface: positive affect, depressed affect, somatic complaints and interpersonal problems (Kohout et al. 1993; Radloff 1977; Ross and Mirowsky 1984). In the 8 item version only two subscales surface, one that captures mood symptoms and one that refers to somatic aspects of depression (Van de Velde et al. 2010; Wallace et al. 2000). Testing the scale in a CFA framework, it has also been established that the CES-D scale represents a continuum rather than forming separate factors for positively and negatively worded items, if correlations between negatively worded items are allowed (Wood et al. 2010).

All fit statistics, both for one or two factors, are acceptable (see Table 3). It is clear that allowing error correlations between negatively worded items significantly improves the models. The two factor model has a better fit, and there is a correlation of 0.82 between both factors, which is still high, but substantially lower than the 0.90 reported in the general population. The data clearly favour the most complex model,

Table 2 Fit statistics for CFA of 15 item CASP scale

\begin{tabular}{lllr}
\hline & RMSEA & CFI & TLI \\
\hline One factor (quality of life) & 0.097 & 0.940 & 0.929 \\
$\quad$ With error correlations & 0.091 & 0.947 & 0.938 \\
Two factors (pleasure/control, autonomy \& self-actualisation) & 0.088 & 0.950 & 0.941 \\
$\quad$ With error correlations & 0.082 & 0.957 & 0.949 \\
Three factors (pleasure/control \& autonomy/self-actualisation) & 0.078 & 0.962 & 0.955 \\
$\quad$ With error correlations & 0.074 & 0.966 & 0.959 \\
\hline
\end{tabular}


Table 3 Fit statistics for CFA of 8 item CES-D scale

\begin{tabular}{clll}
\hline & RMSEA & CFI & TLI \\
\hline 1 factor (depressive symptoms) & 0.077 & 0.971 & 0.960 \\
With error correlations & 0.065 & 0.981 & 0.971 \\
2 factors (somatic/mood symptoms) & 0.053 & 0.987 & 0.981 \\
With error correlations & 0.035 & 0.995 & 0.992 \\
\hline
\end{tabular}

with two factors and error correlations between the negatively worded items, reflecting the salience of the division between somatic and mood aspects of depression in an older population.

\section{General Health Questionnaire (GHQ)}

The GHQ is a 12 item scale, intended as a general screening instrument for psychiatric morbidity (Goldberg and Williams 1988). Most researchers examining the factor structure have focused on the number of sub dimensions. While a large part of the scientific work has been highlighting the plausibility of a three factor structure (anxiety, social dysfunction and loss of confidence) instead of the original one factor (Graetz 1991; Shevlin and Adamson 2005), recently the inclusion of method effects of negative wording has shown this multidimensionality to be a measurement artefact (Hankins 2008). An alternative specification distinguishes positive from negative items in a two dimensional model (Graetz 1991).

Our test on a representative sample of community dwelling people aged 50 or older seems to confirm these findings, showing a relatively robust one factor solution, if we adjust for negative item wording (see Table 4). Since there is a significant difference in fit between the specifications with error correlations and the method factor, allowing the error correlations might be masking substantial aspects of the scale. Therefore the three dimensional model is preferred to allow a finegrained conceptual analysis.

\section{Satisfaction with Life Scale (SWLS)}

The satisfaction with life scale (Diener et al. 1985) is commonly seen as a one dimensional scale for global life satisfaction, comprising five items (Pavot and Diener 1993), but sometimes a single item is used (Morrison et al. 2011). A two factor structure, with one factor referring to the past and another to the present, has equally

Table 4 Fit statistics for CFA of 12 item GHQ scale

\begin{tabular}{lllr}
\hline & RMSEA & CFI & TLI \\
\hline 1 factor (mental health) & 0.148 & 0.913 & 0.893 \\
$\quad$ With error correlations & 0.080 & 0.982 & 0.969 \\
With method factor & 0.092 & 0.970 & 0.959 \\
2 factors (positive/negative items of mental health) & 0.094 & 0.965 & 0.957 \\
3 factors (anxiety/social dysfunction/loss of confidence) & 0.085 & 0.973 & 0.965 \\
\hline
\end{tabular}


been reported for older respondents, and in different cultures than the US (Hultell and Petter Gustavsson 2008; Oishi 2006; Pons et al. 2000). These two factors are very closely related in most studies (correlation around 0.90 ). Since all items are worded in the same sense, a method factor is not necessary.

Both the one factor and two factor model do not seem to fit very well according to the RMSEA, but have a very good fit according to the CFI (Table 5). The two factor model seems marginally better, but the correlation between both factors is very high (0.938). It is a quite surprising finding that a common instrument to measure subjective well-being does not seem to suit particularly well for older respondents in England. Modification indices indicate that being satisfied with life (item c) is more closely related to evaluating one's life as ideal (item a), and less to perceiving one's life conditions as ideal. We allow this correlation, and keep in mind that conditions seem to be less important for life satisfaction among the elderly in the UK.

\section{Well-Being Measures Combined: A Second Order Measure of Well-Being}

Having an indication on the structure of separate aspects of well-being, allows to investigate to what extent these different aspects coincide. As each scale allows a different set of answering categories, putting everything in one analysis can only yield limited results. The CES-D items are binary in nature, while both CASP and GHQ provide 5 response categories and the SWLS 7. Although the CASP and GHQ items have the same number of answering possibilities, their meaning differs as in CASP the frequency of something happening is asked for, while in GHQ the respondent is asked to compare the something with their 'usual' behaviour. This means that the highest correlations between sub-dimensions will logically occur within the same scale. Second order factor analysis, or constructing latent factors out of factors, makes it possible to investigate these interrelations.

As a starting point for the second order analysis, the correlations between the different aspects of well-being, seen here as 10 first order factors, is presented in Table 6. Correlations lower than 0.60 are considered weak, while correlations higher than 0.75 are considered strong. As expected, the highest correlations can be observed between subscales derived from a similar instrument. More relevant for the topic of this paper, is that a number of concepts only are weakly related to each other. Satisfaction with life in general can be seen as only weakly related to most aspects of mental health, which is indicated by the moderate correlations with most subscales of the GHQ and CES-D. On the other hand satisfaction with life, especially in the present, is strongly related to self-actualisation. Anxiety is closely related to symptoms of a depressive mood, but less to self-actualisation and pleasure. Loss of confidence seems closely associated with low control and autonomy. Somatic symptoms of depression are especially weakly related to satisfaction with past life, and only moderately with

Table 5 Fit statistics for CFA of 5 item SWLS scale

\begin{tabular}{llll}
\hline & RMSEA & CFI & TLI \\
\hline 1 factor (life satisfaction) & 0.159 & 0.994 & 0.987 \\
2 factor (past/present life satisfaction) & 0.144 & 0.996 & 0.990 \\
With error correlation between a and c & 0.131 & 0.997 & 0.991
\end{tabular}


Table 6 Overview of correlations between first order factors $(n=8236)$

\begin{tabular}{|c|c|c|c|c|c|c|c|c|c|}
\hline & $\begin{array}{l}\text { SWLS } \\
\text { present }\end{array}$ & $\begin{array}{l}\text { SWLS } \\
\text { past }\end{array}$ & $\begin{array}{l}\text { GHQ } \\
\text { anxiety }\end{array}$ & $\begin{array}{l}\text { GHQ } \\
\text { social } \\
\text { dysfunction }\end{array}$ & $\begin{array}{l}\text { GHQ } \\
\text { loss of } \\
\text { confidence }\end{array}$ & $\begin{array}{l}\text { CES-D } \\
\text { somatic }\end{array}$ & $\begin{array}{l}\text { CES-D } \\
\text { mood }\end{array}$ & $\begin{array}{l}\text { CASP } \\
\text { control \& } \\
\text { autonomy }\end{array}$ & $\begin{array}{l}\text { CASP } \\
\text { self-realisation }\end{array}$ \\
\hline SWLS past & 0.926 & & & & & & & & \\
\hline $\begin{array}{l}\text { GHQ } \\
\text { anxiety }\end{array}$ & 0.609 & 0.527 & & & & & & & \\
\hline $\begin{array}{l}\text { GHQ social } \\
\text { dysfunction }\end{array}$ & 0.579 & 0.454 & 0.715 & & & & & & \\
\hline $\begin{array}{l}\text { GHQ loss of } \\
\text { confidence }\end{array}$ & 0.593 & 0.521 & 0.857 & 0.748 & & & & & \\
\hline $\begin{array}{l}\text { CES-D } \\
\text { somatic }\end{array}$ & -0.508 & -0.384 & -0.664 & -0.630 & -0.617 & & & & \\
\hline CES-D mood & -0.628 & -0.544 & -0.766 & -0.703 & -0.674 & 0.834 & & & \\
\hline $\begin{array}{l}\text { CASP } \\
\text { control \& } \\
\text { autonomy }\end{array}$ & 0.730 & 0.641 & 0.666 & 0.589 & 0.717 & -0.640 & -0.656 & & \\
\hline $\begin{array}{l}\text { CASP self- } \\
\text { realisation }\end{array}$ & 0.779 & 0.753 & 0.546 & 0.617 & 0.607 & -0.667 & -0.639 & -0.847 & \\
\hline $\begin{array}{l}\text { CASP } \\
\text { pleasure }\end{array}$ & 0.710 & 0.732 & 0.582 & 0.566 & 0.648 & -0.512 & -0.646 & -0.790 & 0.886 \\
\hline
\end{tabular}

satisfaction with life in the present, or pleasure. In general depressed mood is slightly closer related to satisfaction with life and general mental health compared to somatic symptoms.

In a next step a number of theoretically grounded second order factor models (Table 7) are tested. This allows drawing conclusions on the most adequate conceptual model to represent subjective well-being in later life. Is well-being in later life best captured by a single second order factor, where all sub-dimensions refer to the same latent concept, as in model 1? Or is a split between eudemonic and hedonic well-being (model 2) more accommodating for our data? A second two dimensional structure

Table 7 Overview of second order structures

\begin{tabular}{|c|c|c|c|c|}
\hline & Model 1 & Model 2 & Model 3 & Model 4 \\
\hline GHQ Anxiety & \multirow{10}{*}{$\begin{array}{l}\text { Subjective Well- } \\
\text { being }\end{array}$} & \multirow{7}{*}{$\begin{array}{l}\text { Hedonic Well- } \\
\text { being }\end{array}$} & \multirow{5}{*}{$\begin{array}{l}\text { Affective Well- } \\
\text { being }\end{array}$} & \multirow{5}{*}{$\begin{array}{c}\text { Hedonic Affective } \\
\text { Well-being }\end{array}$} \\
\hline $\begin{array}{l}\text { GHQ Social } \\
\text { dysfunction }\end{array}$ & & & & \\
\hline $\begin{array}{l}\text { GHQ Loss of } \\
\text { confidence }\end{array}$ & & & & \\
\hline CES-D Somatic & & & & \\
\hline CES-D Mood & & & & \\
\hline SWLS Present & & & \multirow{5}{*}{$\begin{array}{l}\text { Cognitive Well- } \\
\text { being }\end{array}$} & \multirow{2}{*}{$\begin{array}{l}\text { Hedonic Cognitive } \\
\text { Well-being }\end{array}$} \\
\hline SWLS Past & & & & \\
\hline $\begin{array}{l}\text { CASP Control } \\
\text { \&Autonomy }\end{array}$ & & \multirow{3}{*}{$\begin{array}{l}\text { Eudemonic Well- } \\
\text { being }\end{array}$} & & \multirow{3}{*}{$\begin{array}{l}\text { Eudemonic Well- } \\
\text { being }\end{array}$} \\
\hline $\begin{array}{l}\text { CASP Self- } \\
\text { Realisation }\end{array}$ & & & & \\
\hline CASP Pleasure & & & & \\
\hline
\end{tabular}


could also be distilled from the literature, in the sense that eudemonia is a part of hedonic cognitive well-being (model 3). A three factor latent structure, which distinguishes a hedonic affective, hedonic cognitive and eudemonic component of wellbeing, could be seen as a compromise between hedonic and eudemonic conceptions of well-being (model 4).

An overview of the model fit of these different second order models is given in Table 8. Factor loadings on the second order factor(s) are consistently high, so they are not mentioned. Specifying a single second order factor (Model 1) means reducing all these aspects of well-being to a single dimension. Although this model has a reasonable fit in terms of RMSEA, this seems less the case for the other fit indices. This means that using a single well-being concept is defendable, but does not fully grasp the complexity of the subject at hand. Adopting the dominant view by separating hedonic from eudemonic well-being (Model 2), does not seem to greatly improve the understanding of the data. The division between hedonic and eudemonic measures seems less substantial than expected, with a correlation of 0.86 between both dimensions. Distinguishing affective from cognitive aspects of well-being (Model 3) on the other hand has a substantial impact, as this model approaches very good fit. The compromise between both two dimensional approaches (Model 4), specifying a dimension of hedonic cognitive, hedonic affective and eudemonic well-being, fits our data very well. The correlations between these higher order measures of well-being give further evidence to the benefit of the three factor solution (Model 4): cognitive aspects of subjective well-being are more closely related to eudemonic $(r=0.85)$ than to affective aspects of well-being $(r=0.69)$.

\section{Conclusions}

This paper investigates the empirical measurement of well-being in later life, by examining a number of commonly used scales and looking at their interrelations. This is important in the context of psycho-social aspects of successful ageing, as in contrast to more biological aspects of health, the assessment of subjective well-being is less structured and standardised. Two approaches to well-being are examined: the dominant approach, hedonic well-being, assumes that well-being emanates from pleasure and the avoidance of painful experiences, however these are defined by the individual. Measuring well-being in this framework tries to capture moods and emotions on one hand, in the form of positive and negative affect, and cognitive evaluations of one's life on the other hand (Diener 1984). A second and more recent approach to well-being, eudemonic well-being, is less unified and consists of several

Table 8 Fit statistics for second order CFA

\begin{tabular}{llll}
\hline & RMSEA & CFI & TLI \\
\hline Model 1 & 0.080 & 0.902 & 0.895 \\
Model 2 & 0.075 & 0.913 & 0.907 \\
Model 3 & 0.062 & 0.940 & 0.936 \\
Model 4 & 0.057 & 0.951 & 0.947 \\
\hline
\end{tabular}


multidimensional approaches (Hyde et al. 2003; Ryan and Deci 2000; Ryff and Keyes 1995). What they have in common is that they assume well-being emerges as a result of the satisfaction of universal human psychological needs, such as autonomy, selfactualisation and control.

To what extent do indicators of these different aspects of well-being, commonly developed by testing on either relatively small groups of students or in population wide large scale surveys, replicate their structure among adults aged 50 or older in England? Both instruments aimed at capturing negative affect, CES-D and GHQ, performed most in line with their expectations. While considering CES-D as a one dimensional instrument screening for depression is acceptable, a more fine grained approach to depression clearly distinguishes somatic aspects from emotional ones. The GHQ measure in a similar vein is acceptable as a one dimensional construct, but allows more nuance when looking at anxiety, social and confidence aspects of mental health separately. Satisfaction with life, the most commonly used measure for well-being, seems to perform relatively poorly. The CASP scale was used in a revised 15 item version, and a balanced three dimensional structure, consisting of control and autonomy, self-realisation and pleasure, was found to be most accurate to measure eudemonic aspects of well-being.

In regard to the nature of well-being, it seems that the difference between hedonic and eudemonic well-being has been exaggerated in the literature. If a multidimensional concept of well-being is adopted, a threefold structure, distinguishing cognitive, affective and eudemonic well-being is most informative. Rather than illustrating a divide between feelings of satisfaction and striving for self-development, self-reported measures of well-being show a strong relationship between both. People who are satisfied in later life tend to feel autonomous, in control and pursue development. Less strong, but still very present, is the relation between satisfaction and flourishing on one hand, and the absence of negative mood on the other. This merits some attention, as satisfaction is often equated with happiness and good mental health. As such, our findings illustrate that Diener (1984) was right in separating moods from evaluations and judgements about life. Eudemonic aspects can hence be seen as a more qualitative aspect of wellbeing, outlining why people are satisfied.

What would help us answer the questions posed in this analysis better, or in other words what are the suggestions for further research and limitations of this study? First of all, access and inclusion to more measures of well-being could broaden our understanding. Our analysis was, from onset on, limited by the available measures, which were not devised to be used in the framework of an overarching theory of wellbeing, and hence used different response categories. As such a larger and more complete set of subjective measures of well-being in old age, with more similarity in terms of response categories could strengthen our findings. Secondly, the real utility of a multidimensional approach lays in its application to substantial research question, such as for example the successful ageing framework. A last suggestion in a similar vein is to strengthen the theoretical work on how eudemonic, affective and cognitive well-being are interrelated. While up until now most research efforts pursuing either hedonic and eudemonic aspects of well-being are rather partisan in nature, and try to contrast and compare the relative merits of each approach, the real way forward lies in capitalising on the inherent value of both approaches. 


\section{Appendix}

\section{SWLS (Diener 1984)}

a. In most ways my life is close to ideal $(n=8077)$

b. The conditions of my life are excellent $(n=8044)$

c. I am satisfied with my life $(n=8120)$

d. So far, I have gotten the important things I want in life $(n=8122)$

e. If I could live my life again, I would change almost nothing $(n=8124)$

Answering categories

1: Strongly agree

2: Agree

3: Slightly agree

4: Neither agree nor disagree

5: Slightly disagree

6: Disagree

7: Strongly disagree

\section{CES-D (Radloff 1977)}

Now think about the past week and the feelings you have experienced.

Please tell me if each of the following was true for you much of the time during the past week.

(Much of the time during past week),

a. You felt depressed? $(n=8222)$

b. You felt that everything you did was an effort? $(n=8221)$

c. Your sleep was restless? $(n=8223)$

d. You were happy? $(n=8207)$

e. You felt lonely? $(n=8222)$

f. You enjoyed life? $(n=8210)$

g. You felt sad? $(n=8217)$

h. You could no get going? $(n=8077)$

Answering categories

1: Yes

2: No

\section{GHQ (Goldberg 1988)}

We should like to know how your health has been in general over the past few weeks. Have you recently... 
a. been able to concentrate on whatever you're doing? $(n=8163)$

b. lost much sleep over worry? $(n=8155)$

c. felt you were playing a useful part in things? $(n=8082)$

d. felt capable of making decisions? $(n=8160)$

e. felt constantly under strain? $(n=8141)$

f. felt you couldn't overcome your difficulties? $(n=8131)$

g. been able to enjoy your normal day-to-day activities? $(n=8155)$

h. been able to face up to your problems? $(n=8154)$

i. been feeling unhappy and depressed? $(n=8153)$

j. $\quad$ been losing confidence in yourself? $(n=8157)$

$\mathrm{k}$. been thinking of yourself as a worthless person? $(n=8153)$

1. been feeling reasonably happy, all things considered? $(n=8149)$

Answering categories

1 Better than usual

2 Same as usual

3 Less than usual

4 Much less than usual

Quality of Life (CASP) (Hyde et al. 2003)

Here is a list of statements that people have used to describe their lives or how they feel. We would like to know how often, if at all, you think they apply to you.

Control

a. My age prevents me from doing the things I would like to. $(n=8143)$

b. I feel that what happens to me is out of control. $(n=8088)$

c. I feel free to plan things for the future. $(n=8063)$

d. I feel left out of things. $(n=8096)$

\section{Autonomy}

e. I can do the things that I want to do. $(n=8110)$

f. Family responsibilities prevent me from doing what I want to do. $(n=8076)$

g. I feel that I can please myself what I can do. $(n=8107)$

h. My health stops me from doing the things I want to do. $(n=8140)$

i. Shortage of money stops me from doing the things I want to do. $(n=8129)$

Pleasure

j. I look forward to each day. $(n=8125)$

k. I feel that my life has meaning. $(n=8094)$

1. I enjoy the things that I do. $(n=8130)$

m. I enjoy being in the company of others. $(n=8148)$

n. On balance, I look back on my life with a sense of happiness. $(n=8117)$ 


\section{Self-realization}

- I feel full of energy these days. $(n=8121)$

- I choose to do things that I have never done before. $(n=8095)$

- I feel satisfied with the way my life has turned out. $(n=8104)$

- I feel that life is full of opportunities. $(n=8089)$

- I feel that the future looks good for me. $(n=8107)$

\section{Answering categories}

\section{Often \\ 2 Sometimes \\ 3 Not often \\ 4 Never}

\section{References}

Alexopoulos, G. S. (2005). Depression in the elderly. Lancet, 365(9475), 1961-1970.

Ariely, G., \& Davidov, E. (2011). Assessment of measurement equivalence with cross-national and longitudinal surveys in political science. European Political Science, 1, 1-15.

Beaumont, J. (2011). Measuring National Well-being - Discussion paper on domains and measures. London.

Beekman, A. T., \& Deeg, D. (1995). Major and minor depression in later life: a study of prevalence and risk factors. Journal of Affective Di, 36, 65-75. doi:10.1111/j.1752-0606.2011.00243.x.

Bollen, K. A. (1989). Structural equations with latent variables (p. 514). Wiley.

Bowling, A., \& Dieppe, P. (2005). What is successful ageing and who should define it? BMJ: British Medical Journal, 331, 1548-1551. Retrieved from http://www.ncbi.nlm.nih.gov/pmc/articles/pmc1322264/.

Bradburn, N. M. (1969). The structure of psychological well-being. Chicago: Aldine.

Brown, T. A. (2003). Confirmatory factor analysis of the Penn State Worry Questionnaire: multiple factors or method effects? Behaviour Research and Therapy, 41(12), 1411-1426. doi:10.1016/S0005-7967(03)00059-7.

Brown, T. A. (2006). Confirmatory factor analysis for applied research. New York: The Guilford Press.

Campbell, A., Converse, P. E., \& Rodgers, W. L. (1976). The quality of American life: Perceptions, evaluations, and satisfactions (p. 583). New York: Russell Sage.

Chen, Y., Rendina-gobioff, G., \& Dedrick, R. F. (2010). Factorial invariance of a Chinese self-esteem scale for third and sixth grade students: evaluating method effects associated with positively and negatively worded items. International Journal of Educational and Psychological Assessment, 6, 21-35.

Deci, E. L., \& Ryan, R. M. (2006). Hedonia, eudaimonia, and well-being: an introduction. Journal of Happiness Studies, 9(1), 1-11. doi:10.1007/s10902-006-9018-1.

Delle Fave, A., Brdar, I., Freire, T., Vella-Brodrick, D., \& Wissing, M. P. (2010). The eudaimonic and hedonic components of happiness: qualitative and quantitative findings. Social Indicators Research, 100(2), 185207. doi:10.1007/s11205-010-9632-5.

Demakakos, P., McMunn, A., \& Steptoe, A. (2010). Well-being in older age: A multidimensional perspective. In J. Banks, C. Lessof, J. Nazroo, N. Rogers, M. Stafford, \& A. Steptoe (Eds.), Financial circumstances, health and well-being of the older population in England. The 2008 English Longitudinal Study of Ageing (pp. 115-177). London: Institute for fiscal studies.

Diener, E. (1984). Subjective well-being. Psychological Bulletin, 95(3), 542-575. Retrieved from http://www. ncbi.nlm.nih.gov/pubmed/21228133.

Diener, E., Emmons, R., Larsen, R. J., \& Griffin, S. (1985). Satisfaction with life scale. Journal of Personality Assessment, 49(1), 71-75.

Diener, E., Sapyta, J. J., \& Suh, E. (1998). Subjective well-being is essential to well-being. Psychological Inquiry, 9(1), 33-37.

Diener, E., Suh, E., \& Lucas, R. E. (1999). Subjective well-being: Three decades of progress. Psychological bulletin, 125(2), 276-302. Retrieved from http://psycnet.apa.org/journals/bul/125/2/276/. 
DiStefano, C., \& Motl, R. W. (2009). Self-esteem and method effects associated with negatively worded items: investigating factorial invariance by sex. Structural Equation Modeling: A Multidisciplinary Journal, 16(1), 134-146. doi:10.1080/10705510802565403.

Easterlin, R. (1974). Does economic growth improve the human lot? Some empirical evidence. In P. A. David \& M. W. Reder (Eds.), Nations and households in economic growth: Essays in honor of Moses Abramovitz (pp. 87-125). New York: Academic.

Giddens, A. (1991). Modernity and self-identity: Self and society in the late modern age. Stanford University Press.

Goldberg, D. P. (1988). A User's Guide to the GHQ. Windsor.

Goldberg, D. P., \& Williams, P. (1988). A user's guide to the General Health Questionnaire. Basingstoke.

Graetz, B. (1991). Multidimensional properties of the General Health Questionnaire. Social Psychiatry and Psychiatric Epidemiology, 26(3), 132-138.

Hankins, M. (2008). The reliability of the twelve-item general health questionnaire (GHQ-12) under realistic assumptions. BMC Public Health, 8, 355. doi:10.1186/1471-2458-8-355.

Henderson, L. W., \& Knight, T. (2012). Integrating the hedonic and eudaimonic perspectives to more comprehensively understand wellbeing and pathways to wellbeing. Internation Journal of Wellbeing, 2(3), 196-221. doi:10.5502/ijw.v2i3.3.

Hu, L., \& Bentler, P. M. (1999). Cutoff criteria for fit indexes in covariance structure analysis: conventional criteria versus new alternatives. Structural Equation Modeling: A, 6(1), 1-55.

Hultell, D., \& Petter Gustavsson, J. (2008). A psychometric evaluation of the satisfaction with life scale in a Swedish nationwide sample of university students. Personality and Individual Differences, 44(5), 10701079. doi:10.1016/j.paid.2007.10.030.

Hyde, M., Wiggins, R. D., Higgs, P., \& Blane, D. (2003). A measure of quality of life in early old age: the theory, development and properties of a needs satisfaction model (CASP-19). Aging \& Mental Health, 7(3), 186-194. doi:10.1080/1360786031000101157.

Inglehart, R. (1997). Modernization and postmodernization: Cultural, economic, and political change in 43 societies. Princeton: Princeton University Press.

Kahneman, D., Krueger, A. B., Schkade, D. A., Schwarz, N., \& Stone, A. a. (2006). Would you be happier if you were richer? A focusing illusion. Science (New York, N.Y.), 312(5782), 1908-10. doi:10.1126/ science. 1129688 .

Kahneman, D., \& Thaler, R. H. (2006). Utility maximization and experienced utility. Journal of Economic Perspectives, 20(1), 221-234.

Kashdan, T. B., Biswas-Diener, R., \& King, L. a. (2008). Reconsidering happiness: the costs of distinguishing between hedonics and eudaimonia. The Journal of Positive Psychology, 3(4), 219-233. doi:10.1080/ 17439760802303044.

King, D. A., \& Markus, H. E. (2000). Mood disorders in older adults. In S. K. Whitbourne (Ed.), Psychopathology in later adulthood (pp. 141-172). New York: Wiley.

Kohout, F. J., Berkman, L. F., Evans, D. a., \& Cornoni-Huntley, J. (1993). Two shorter forms of the CES-D depression symptoms index. Journal of Aging and Health, 5(2), 179-193. doi:10.1177/ 089826439300500202.

Lebowitz, B. D., Pearson, J. L., Schneider, L. S., Reynolds, C. F., Alexopoulos, G. S., Bruce, M. L., \& Parmelee, P. A. (1997). Diagnosis and treatment of depression in late life consensus statement update. In Jama The Journal Of The American Medical Association, 278, 1186-1190.

Marmot, M., Banks, J., Blundell, R., Erens, B., Lessof, C., Nazroo, J., \& Huppert, F. A. (2011). English longitudinal study of ageing: Wave 0 (1998, 1999 and 2001) and Waves 1-4 (2002-2009). Colchester: UK Data Archive.

Marsh, H. W. (1996). Positive and negative global self-esteem: a substantively meaningful distinction or artifactors? Journal of Personality and Social Psychology, 70(4), 810-819.

Maslow, A. (1968). Towards a psychology of being. New York: Van Nostrand.

Meredith, W. (1993). Measurement invariance, factor analysis and factorial invariance. Psychometrika, 58(4), 525-543.

Morrison, M., Tay, L., \& Diener, E. (2011). Subjective well-being and national satisfaction: findings from a worldwide survey. Psychological Science, 22(2), 166-171. doi:10.1177/0956797610396224.

Muthén, L. K., \& Muthén, B. O. (2010). Mplus user's guide (6th ed.). Los Angeles: Muthen \& Muthen.

OECD. (2011). How's life? Measuring Well-being (p. 286). OECD Publishing.

Oishi, S. (2006). The concept of life satisfaction across cultures: An IRT analysis. Journal of Research in Personality, 40(4), 411-423. doi:10.1016/j.jrp.2005.02.002.

Pavot, W., \& Diener, E. (1993). Review of the satisfaction with life scale. Psychological Assessment, 5(2), 164. 
Pons, D., Atienza, F. L., Balaguer, I., \& García-Merita, M. L. (2000). Satisfaction with life scale: analysis of factorial invariance for adolescents and elderly persons. Perceptual and Motor Skills, 91(1), 62-68.

Radloff, L. S. (1977). The CES-D scale: a self-report depression scale for research in the general population. Applied Psychological Measurement, 1(3), 285-401.

Ross, C. E., \& Mirowsky, J. (1984). Components of depressed mood in married men and women. American Journal of Epidemiology, 119(6), 997-1004.

Rowe, J. W., \& Kahn, R. L. (1997). Successful ageing. The Gerontologist, 37(4), 433-440.

Ryan, R. M., \& Deci, E. L. (2000). Self-determination theory and the facilitation of intrinsic motivation, social development, and well-being. The American Psychologist, 55(1), 68-78.

Ryan, R. M., \& Deci, E. L. (2001). On happiness and human potentials: a review of research on hedonic and eudaimonic well-being. Annual Review of Psychology, 52(1), 141-166.

Ryff, C. D. (1989). Beyond Ponce de Leon and life satisfaction: new directions in quest of successful ageing. International Journal of Behavioral Development, 12(1), 35-55. doi:10.1177/016502548901200102.

Ryff, C. D., \& Keyes, C. L. M. (1995). The structure of psychological well-being revisited. Journal of Personality and Social Psychology, 69(4), 719.

Ryff, C. D., \& Singer, B. H. (1998). The contours of positive human health. Psychological Inquiry, 9(1), 1-28.

Ryff, C. D., Singer, B. H., \& Dienberg Love, G. (2004). Positive health: connecting well-being with biology. Philosophical Transactions of the Royal Society of London, Series B, Biological Sciences, 359(1449), 1383-1394. doi:10.1098/rstb.2004.1521.

Scholes, S., Medina, J., Cheshire, H., \& Cox, K. (2009). Living in the 21st Century: Older People in England. The 2006 English Longitudinal Study of Ageing, (5050).

Seligman, M. E. P., \& Csikszentmihalyi, M. (2000). Positive psychology: an introduction. American Psychologist, 55(1), 5.

Sexton, E., King-Kallimanis, B. L., Conroy, R. M., \& Hickey, A. (2013). Psychometric evaluation of the CASP-19 quality of life scale in an older Irish cohort. Quality of Life Research: An International Journal of Quality of Life Aspects of Treatment, Care and Rehabilitation. doi:10.1007/s11136-013-0388-7.

Shevlin, M., \& Adamson, G. (2005). Alternative factor models and factorial invariance of the GHQ-12: a large sample analysis using confirmatory factor analysis. Psychological Assessment, 17(2), 231-236. doi:10. 1037/1040-3590.17.2.231.

Stiglitz, J., Sen, A., \& Fitoussi, J. (2009). Report by the commission on the measurement of economic performance and social progress. Performance and Social Progress (p. 291).

Strawbridge, W. J., Wallhagen, M. I., \& Cohen, R. D. (2002). Successful aging and well-being: self-rated compared with Rowe and Kahn. The Gerontologist, 42(6), 727-733.

Taylor, S. E., \& Brown, J. D. (1988). Illusion and well-being: a social psychological perspective on mental health. Psychological Bulletin, 103(2), 193-210.

Van de Velde, S., Bracke, P., Levecque, K., \& Meuleman, B. (2010). Gender differences in depression in 25 European countries after eliminating measurement bias in the CES-D 8. Social Science Research, 39(3), 396-404. doi:10.1016/j.ssresearch.2010.01.002.

Van den Berg, M. D., Oldehinkel, a. J., Bouhuys, a. L., Brilman, E. I., Beekman, A. T., \& Ormel, J. (2001). Depression in later life: three etiologically different subgroups. Journal of Affective Disorders, 65(1), 19-26.

Vanhoutte, B. (2012). Measuring subjective well-being in later life: A review. Manchester.

Wallace, R. B., Herzog, A. R., Ofstedal, M. B., Steffick, D., Fonda, S., \& Langa, K. M. (2000). Documentation of affective functioning measures in the health and retirement study. Ann Arbor: MI.

Waterman, A. S. (1993). Two conceptions of happiness: contrasts of personal expressiveness (eudaimonia) and hedonic enjoyment. Journal of Personality and Social Psychology, 64(4), 678-691.

Waterman, A. S. (2007). On the importance of distinguishing hedonia and eudaimonia when contemplating the hedonic treadmill. The American Psychologist, 62(6), 612-613. doi:10.1037/0003-066X62.6.612.

Waterman, A. S. (2008). Reconsidering happiness: a eudaimonist's perspective. The Journal of Positive Psychology, 3(4), 234-252. doi:10.1080/17439760802303002.

Watson, D., Clark, L. A., \& Tellegen, A. (1988). Development and validation of brief measures of positive and negative affect: the PANAS scales. Journal of Personality and Social Psychology, 54(6), 1063-1070.

Wiggins, R. D., Netuveli, G., Hyde, M., Higgs, P., \& Blane, D. (2008). The evaluation of a self-enumerated scale of quality of life (CASP-19) in the context of research on ageing: a combination of exploratory and confirmatory approaches. Social Indicators Research, 89(1), 61-77. doi:10.1007/s11205-007-9220-5.

Wood, A. M., Taylor, P. J., \& Joseph, S. (2010). Does the CES-D measure a continuum from depression to happiness? Comparing substantive and artifactual models. Psychiatry Research, 177(1-2), 120-123. doi:10.1016/j.psychres.2010.02.003. 